\title{
The novel Coronavirus disease (COVID-19) pandemic: Knowledge, attitude, practice, and perceived stress among health care workers in Karachi, Pakistan
}

\author{
Fatima Jawed*1 (1), Sana Manazir ${ }^{1}$, Arhama Zehra $^{1}$, Ramsha Riaz $^{1}$
}

Received: 14 Jun 2020

Published: 7 Oct 2020

Abstract

Background: The Coronavirus disease (COVID-19) has created chaos across the globe. Health care workers having close contact with infected individuals play a decisive role in infection control. This study assessed the level of knowledge, attitude, practice (KAP) and perceived stress among health care workers of Karachi, Pakistan.

Methods: A cross sectional study was performed between March 11, 2020 and March 25, 2020 among health care workers of Karachi, Pakistan. Data were collected through an online, self-administered questionnaire. The level of KAP was categorized using modified Bloom's cut off point. Chi-square test, independent sample t test, and one-way ANOVA were used to analyze the data with Statistical Package for Social Sciences (SPSS) version 24.0.

Results: A total of 304 health care workers responded to the survey. The most popular source of information was found to be TV/radio/newspaper. Although 54.3\%, 75\%, and 58.9\% respondents had good knowledge, good attitude, and good practice, respectively, more than $40 \%$ of respondents did not use gloves during patient interaction. Most of participants rated their level of knowledge as moderate and were inclined towards the need for more training. Around $80 \%$ of participants had either moderate stress or severe perceived stress.

Conclusion: Our study revealed a relatively good level of KAP among respondents, but there is a need for further training programs. This study yielded high stress levels among respondents, with personal and family safety being the main concerns. The government should, therefore, take proper measures to alleviate the stress levels to provide a strong frontline force.

Keywords: Novel coronavirus, COVID-19, SARS-CoV-2, Pandemic, KAP, Perceived stress, Health care workers, Pakistan

Conflicts of Interest: None declared

Funding: None

*This work has been published under CC BY-NC-SA 1.0 license.

Copyright $\subseteq$ Iran University of Medical Sciences

Cite this article as: Jawed F, Manazir S, Zehra A, Riaz R. The novel Coronavirus disease (COVID-19) pandemic: Knowledge, attitude, practice, and perceived stress among health care workers in Karachi, Pakistan. Med J Islam Repub Iran. 2020 (7 Oct);34:132. https://doi.org/10.47176/mjiri.34.132

\section{Introduction}

The ongoing novel coronavirus disease (COVID-19) pandemic is a highly contagious and rapidly changing disease caused by a newly discovered virus, belonging to beta-

Corresponding author: Dr Fatima Jawed, fatimajawed103@gmail.com

Dow Medical College, Dow University of Health Sciences, Baba-e-Urdu Road, Karachi, Pakistan coronavirus family which includes Severe Acute Respiratory Syndrome Coronavirus (SARS-CoV) and Middle East Respiratory Syndrome Coronavirus (MERS-CoV) (1-3). A

$\uparrow$ What is "already known" in this topic:

In an outbreak of a pandemic like Coronavirus disease (COVID19), the health care workers (HCWs) face significant physical and mental burdens. They have to deal with infected individuals and at the same time try to increase public awareness about the disease and preventive measures.

$\rightarrow$ What this article adds:

This study showed the level of knowledge, attitude, and practice (KAP) among HCWs of Karachi was comparatively good. Doctors had better KAP. Most of participants had either "moderate" or "severe" perceived stress levels. Stress scores were associated with HCWs' age, gender, years of experience, having children, and living status. 
previous study published after past outbreaks of other coronavirus specie has warned of a possible reemergence of a similar outbreak in the future, on account of the presence of SARS-CoV like viruses in bats (4). The novel coronavirus, formerly known as the 2019-nCoV, was renamed by the International Committee on Taxonomy of Viruses as Severe Acute Respiratory Syndrome Coronavirus-2 (SARS-CoV2), which first emerged in Wuhan, China, in December 2019 as a cluster of respiratory illnesses $(1,2)$.

Owing to serious health threats and rapid and unceasing transmission of virus across various countries, the World Health Organization (WHO) announced the COVID-19 outbreak as the sixth public health emergency of international concern on January 30, 2020, and as a pandemic on March 11, 2020 (2, 5). COVID-19 mainly spreads via respiratory droplets and around $20 \%$ of the cases can result in very serious conditions like acute respiratory distress syndrome (ARDS), septic shock, and multiorgan failure, and $2 \%$ can be fatal (3). Currently, no vaccine or drug treatment is available (6). Therefore, the only way to tackle the situation is to correctly practice the infection prevention and control guidelines. Apart from the physical effects, it can also result in serious psychological and social consequences (7).

As reported by the WHO, by May 31, 2020, there had been more than 5.9 million confirmed COVID-19 cases and 368000 deaths due to COVID-19 across the globe, 64496 confirmed cases, and 1483 deaths of which are confined to Pakistan (8). In Pakistan, the first case of coronavirus was reported on February 26, 2020 and the number of confirmed cases increased to 10000 on April 23, 2020 (8). On May 31, 2020, COVID-19 cases have jumped to 64496 (8). This highlights that COVID-19 case trajectory continues to constantly and rapidly rise within Pakistan.

Pakistan is facing serious health threats. Health care workers (HCWs) being on the frontline and in direct contact with COVID-19 patients, are at high risk of getting infected because of their continued exposure at health facilities (9). As COVID-19 cases are persistently rising, it places greater responsibility on HCWs, ultimately increasing physical and mental burden. According to a study, around $20 \%$ of health care professionals have become infected in Italy (10). A study from China has shown that $71.5 \%$ of HCWs had symptoms of distress (11). Studies conducted during past outbreaks have also reported that an increasing number of cases, increased workload, lack of disease treatment, fear of being infected, transmitting it to their family, stigmatization, and overwhelming media news were potentially distressing for HCWs (11).

HCWs are also being approached for raising awareness among the general population; therefore, as a prerequisite, HCWs should have adequate knowledge. A study conducted among HCWs in Saudi Arabia revealed poor knowledge and infection control practice towards MERS$\mathrm{CoV}$ (12). HCWs' stress may also influence their efficacy in a pandemic situation; hence, recognizing the stressors is of utmost importance to develop approaches to cope with them. Moreover, very few studies on COVID-19 have been conducted on HCWs in Karachi, Pakistan. Therefore, assessing the perceived stress, awareness, and preparedness of HCWs is imperative in COVID-19 prevention and control. Hence, this study aimed to assess the level of knowledge, attitude, practice (KAP), and perceived stress among the health care workers of Karachi, Pakistan, during the COVID-19 pandemic.

\section{Methods}

This descriptive, analytic cross sectional survey was conducted between March 11, 2020 and March 25, 2020 among HCWs employed in public and private health care sector, in Karachi, Pakistan. The population targeted consisted of HCWs, including doctors, nurses, and allied health professionals. HCWs who have been out of practice during COVID-19 outbreak due to any reason were excluded. A health care worker $(\mathrm{HCW})$ is defined as the one who is directly or indirectly involved in the process of delivering health care services to the sick and injured (13). Allied health professionals are the wide range of health professionals who are neither physicians nor nurses but play a significant supportive role in providing health services and can be categorized into technicians and technologists (14).

Sample size was calculated to be 384 based on the assumption that $50 \%$ of the health care workers had sufficient knowledge regarding the novel coronavirus disease (COVID-19), which was increased to 800 to obtain maximum responses. For data collection, participants were recruited through the social media groups of health professionals. We approached 800 participants through their social media accounts, including 400 doctors, 240 nurses, and 160 allied health professionals. The questionnaire link was sent only to those who responded and agreed to participate in the survey to ensure quality. Out of the 800 participants approached, 304 completed the survey, including 180 doctors, 76 nurses, and 48 allied health professionals, with an overall response rate of $38 \%$. Consent was obtained by all participants, and confidentiality and anonymity were maintained.

The self-administered questionnaire was formulated after going through current information, guidelines by WHO, and relevant data available on the topic $(6,12,15,16)$. The questionnaire was made available online via Google forms. A preliminary survey to 10 participants was conducted to validate and modify the questionnaire accordingly. The final version of the questionnaire was divided into 6 main sections: sociodemographic, knowledge, attitude, practice, stress, and training requirements regarding emerging infectious diseases. The sociodemographic section included questions about general details of respondents, such as age, gender, professional status, years of experience, marital status, living arrangements, and sources of knowledge. The knowledge section consisted of 16 items that aimed at assessing the knowledge about incubation period, transmission, fatality rate, symptoms, risk factors, and treatment of COVID-19. In the attitude section, 6 items were used to assess respondents' perception towards the spread, severity, and prevention of COVID-19. In the subsequent section, 5 items of practice were used to evaluate the compliance of infection control and preventive measures. This was followed by the perceived stress section, comprising 10 items that inquired about potential factors that could have been 
the stressors among respondents during the COVID-19 outbreak. The last section consisted of 2 items that explored the perception of HCWs regarding the level of their knowledge and the need of educational courses about COVID-19 and other emerging infectious diseases.

For the knowledge section, every correct answer was assigned one point and incorrect or uncertain (don't know) response zero point. The expected knowledge score was between 0 to 16 points. In the attitude section, each item was scored on a 5-point Likert scale, ranging from one (strongly disagree) to 5 (strongly agree). The attitude score was obtained by adding scores of all items, ranging from 6 to 30 points. High attitude scores signified positive attitude and low scores negative attitude. For the practice section, a score of one was allotted for choosing the answer reflecting good practice and 0 for choosing the answer reflecting poor practice. The expected practice score was between 0 to 5 points. HCWs' KAP levels were categorized as 'good', 'moderate', and 'poor' based on modified Bloom's cut off point (17). Respondents with KAP scores of $80 \%-100 \%$ were considered as good, while respondents within the range of 50\%-79\% were classified as moderate, and scores of $<50 \%$ were grouped as poor.

The perceived stress section consisted of 10 items, each of which was scored on a Likert response scale ranging from 0 (never) to 4 (always). The perceived stress score was obtained by adding scores of all items, ranging from 0 to 40 points. High scores signified high levels of perceived stress, while low scores indicated lower levels of perceived stress. The internal consistency coefficient (Cronbach's $\alpha$ ) for severity of stress was 0.92 . The level of perceived stress among HCWs was categorized as 'no stress', 'mild stress', 'moderate stress', and 'severe stress'. Respondents with perceived stress scores of $76 \%-100 \%$ were considered as having severe stress, those with scores of $51 \%-75 \%$ as having moderate stress, while respondents with scores ranging from $26 \%-50 \%$ as having mild stress, and scores between $0 \%-25 \%$ as having no stress.

Data were tabulated in Microsoft Excel 2016 and analyzed using Statistical Package for Social Sciences (SPSS) version 24.0 (IBM Corp., Armonk, NY). Descriptive statistical analysis, including frequencies, percentage, mean, and standard deviations were used for categorical and continuous variables, respectively. The chi-square test, independent sample t test, and one-way ANOVA were performed to determine the association between sociodemographic variables, KAP, and perceived stress levels. A p-value $<0.05$ was considered statistically significant.

\section{Results}

The study comprised a total of 304 health care workers; more than half of whom were doctors and females $(59.2 \%$ and $54.6 \%$, respectively). The mean age of participants was $34.32 \pm 8.51$, while the mean years of experience were $8.13 \pm 7.15$. Around two-thirds of the study population was married and out of those, three-fourths of the participants had children. Most of health care workers were living with their families at the time of COVID-19 outbreak. The demographics of the study participants are summarized in Table 1.

Knowledge and attitude of participants was assessed about coronavirus disease as shown in Table 2. Also, most of participants $(n=274)$ correctly identified mode of transmission, while only half of them knew the fatality rate of COVID-19. Around $80 \%$ of health care workers either agreed or strongly agreed that the government should isolate infected patients in special hospitals. Of the 304 participants, $47.7 \%$ agreed while $31.9 \%$ strongly agreed that after COVID-19 outbreak, they will be keener to apply infection prevention and control measures.

Health care workers were also inquired regarding symptoms and risk factors of COVID-19 as shown in Figure 1. Most of the participants were aware of fever (91.8\%), dry cough $(91.4 \%)$, and shortness of breath $(90.1 \%)$ as being the predominant symptoms of coronavirus disease. Similarly, a preponderance among the responses regarding the risk factors "close contact with infected individuals" $(95.4 \%)$ and "travelers from infected countries" (91.4\%) was observed.

The participants were inquired about the sources of information regarding coronavirus disease and the major sources were found to be TV/radio/newspaper, social media, and WHO website, respectively, as shown in Figure 2.

The participants of the study were questioned regarding

Table 1. Socio-demographics of the study population $(\mathrm{n}=304)$

\begin{tabular}{|c|c|c|c|c|c|c|}
\hline & & \multicolumn{3}{|c|}{ Health care workers } & & \multirow[t]{2}{*}{ p-value } \\
\hline & & $\begin{array}{l}\text { Doctors } \\
\text { N }(\%) \\
\end{array}$ & $\begin{array}{l}\text { Nurses } \\
\mathrm{N}(\%)\end{array}$ & $\begin{array}{l}\text { Allied health professionals } \\
\mathrm{N}(\%) \\
\end{array}$ & $\begin{array}{r}\text { Total } \\
\mathrm{N}(\%) \\
\end{array}$ & \\
\hline Number of participants & & $180(59.2)$ & $76(25.0)$ & $48(15.8)$ & $304(100.0)$ & \\
\hline Age $($ mean $) \pm \mathrm{SD}$ & & $35.24 \pm 8.97$ & $31.74 \pm 7.45$ & $34.96 \pm 7.61$ & $34.32 \pm 8.51$ & 0.01 \\
\hline \multirow[t]{2}{*}{ Gender } & Female & $93(51.7)$ & $49(64.5)$ & $24(50.0)$ & $166(54.6)$ & \multirow[t]{2}{*}{0.13} \\
\hline & Male & $87(48.3)$ & $27(35.5)$ & $24(50.0)$ & $138(45.4)$ & \\
\hline Years of experience (mean) $\pm \mathrm{SD}$ & & $8.42 \pm 7.78$ & $6.42 \pm 5.54$ & $9.75 \pm 6.47$ & $8.13 \pm 7.15$ & 0.03 \\
\hline \multirow[t]{2}{*}{ Marital status } & Yes & $120(66.7)$ & $50(65.8)$ & $32(66.7)$ & $202(66.4)$ & \multirow[t]{2}{*}{0.99} \\
\hline & No & $60(33.3)$ & $26(34.2)$ & $16(33.3)$ & $102(33.6)$ & \\
\hline \multirow{2}{*}{ Have children } & Yes & $91(75.8)$ & $34(68.0)$ & $24(75.0)$ & $149(73.8)$ & \multirow[t]{2}{*}{0.56} \\
\hline & No & $29(24.2)$ & $16(32.0)$ & $8(25.0)$ & $53(26.2)$ & \\
\hline \multirow{2}{*}{$\begin{array}{l}\text { Living with family at the time of } \\
\text { COVID-19 outbreak }\end{array}$} & Yes & $148(82.2)$ & $70(92.1)$ & $34(70.8)$ & $252(82.9)$ & \multirow[t]{2}{*}{0.01} \\
\hline & No & $32(17.8)$ & $6(7.9)$ & $14(29.2)$ & $52(17.1)$ & \\
\hline
\end{tabular}

SD: Standard deviation

${ }^{\mathrm{a}}$ Calculated using chi-square for categorical data and one-way ANOVA test for continuous data; $\mathrm{p}$-value of $<0.05$ was considered statistically significant. 


\begin{tabular}{|c|c|c|c|c|c|}
\hline \multicolumn{6}{|l|}{ Knowledge about COVID-19 } \\
\hline & & & $\begin{array}{l}\text { Correct } \\
\mathrm{N}(\%)\end{array}$ & $\begin{array}{c}\text { Incorrect } \\
\mathrm{N}(\%)\end{array}$ & $\begin{array}{c}\text { Don't know } \\
\mathrm{N}(\%)\end{array}$ \\
\hline \multicolumn{3}{|c|}{$\begin{array}{l}\text { Is Novel Coronavirus disease (COVID-19) same as Severe Acute Respiratory Disease } \\
\text { (SARS) and Middle East Respiratory Syndrome (MERS)? }\end{array}$} & $147(48.4)$ & $46(15.1)$ & $111(36.5)$ \\
\hline \multicolumn{3}{|c|}{ The incubation period of COVID-19 is $1-14$ days? } & $235(77.3)$ & $5(1.6)$ & $64(21.1)$ \\
\hline \multicolumn{3}{|l|}{ COVID-19 is transmitted through small air droplets? } & $274(90.1)$ & $5(1.6)$ & $25(8.2)$ \\
\hline \multicolumn{3}{|l|}{ According to WHO the fatality rate of COVID- 19 is $2 \%$ ? } & $159(52.3)$ & $32(10.5)$ & $113(37.2)$ \\
\hline \multicolumn{3}{|l|}{ Is there any vaccine or drug treatment for COVID- 19 ? } & $194(63.8)$ & $19(6.3)$ & $91(29.9)$ \\
\hline \multicolumn{3}{|l|}{ Are antibiotics effective against COVID-19? } & $199(65.5)$ & $34(11.2)$ & $71(23.4)$ \\
\hline \multicolumn{6}{|l|}{ Attitude about COVID-19 } \\
\hline & $\begin{array}{c}\text { Strongly disagree } \\
\mathrm{N}(\%) \\
\end{array}$ & $\begin{array}{l}\text { Disagree } \\
\mathrm{N}(\%) \\
\end{array}$ & $\begin{array}{l}\text { Neutral } \\
\mathrm{N}(\%)\end{array}$ & $\begin{array}{l}\text { Agree } \\
\mathrm{N}(\%) \\
\end{array}$ & $\begin{array}{l}\text { Strongly agree } \\
\mathrm{N}(\%)\end{array}$ \\
\hline $\begin{array}{l}\text { Overcrowding in emergency department and poor hand } \\
\text { hygiene contributes to risk of healthcare workers being } \\
\text { infected with COVID-19 }\end{array}$ & $8(2.6)$ & $0(0.0)$ & $41(13.5)$ & $144(47.4)$ & $111(36.5)$ \\
\hline $\begin{array}{l}\text { Lack of knowledge about mode of transmission and in- } \\
\text { fection control measures contributes to increased risk } \\
\text { of COVID-19 }\end{array}$ & $7(2.3)$ & $3(1.0)$ & $41(13.5)$ & $158(52.0)$ & $95(31.3)$ \\
\hline COVID-19 is more dangerous than common flu & $6(2.0)$ & $10(3.3)$ & $63(20.7)$ & $167(54.9)$ & $58(19.1)$ \\
\hline $\begin{array}{l}\text { After COVID-19 outbreak, you are keener to apply in- } \\
\text { fection prevention and control measures }\end{array}$ & $8(2.6)$ & $0(0.0)$ & $54(17.8)$ & $145(47.7)$ & 97 (31.9) \\
\hline $\begin{array}{l}\text { Government should arrange awareness sessions to pre- } \\
\text { vent infection }\end{array}$ & $6(2.0)$ & $0(0.0)$ & $62(20.4)$ & $146(48.0)$ & $90(29.6)$ \\
\hline $\begin{array}{l}\text { Government should isolate infected patient in special } \\
\text { hospitals }\end{array}$ & $8(2.6)$ & $0(0.0)$ & $46(15.1)$ & $137(45.1)$ & $113(37.2)$ \\
\hline
\end{tabular}
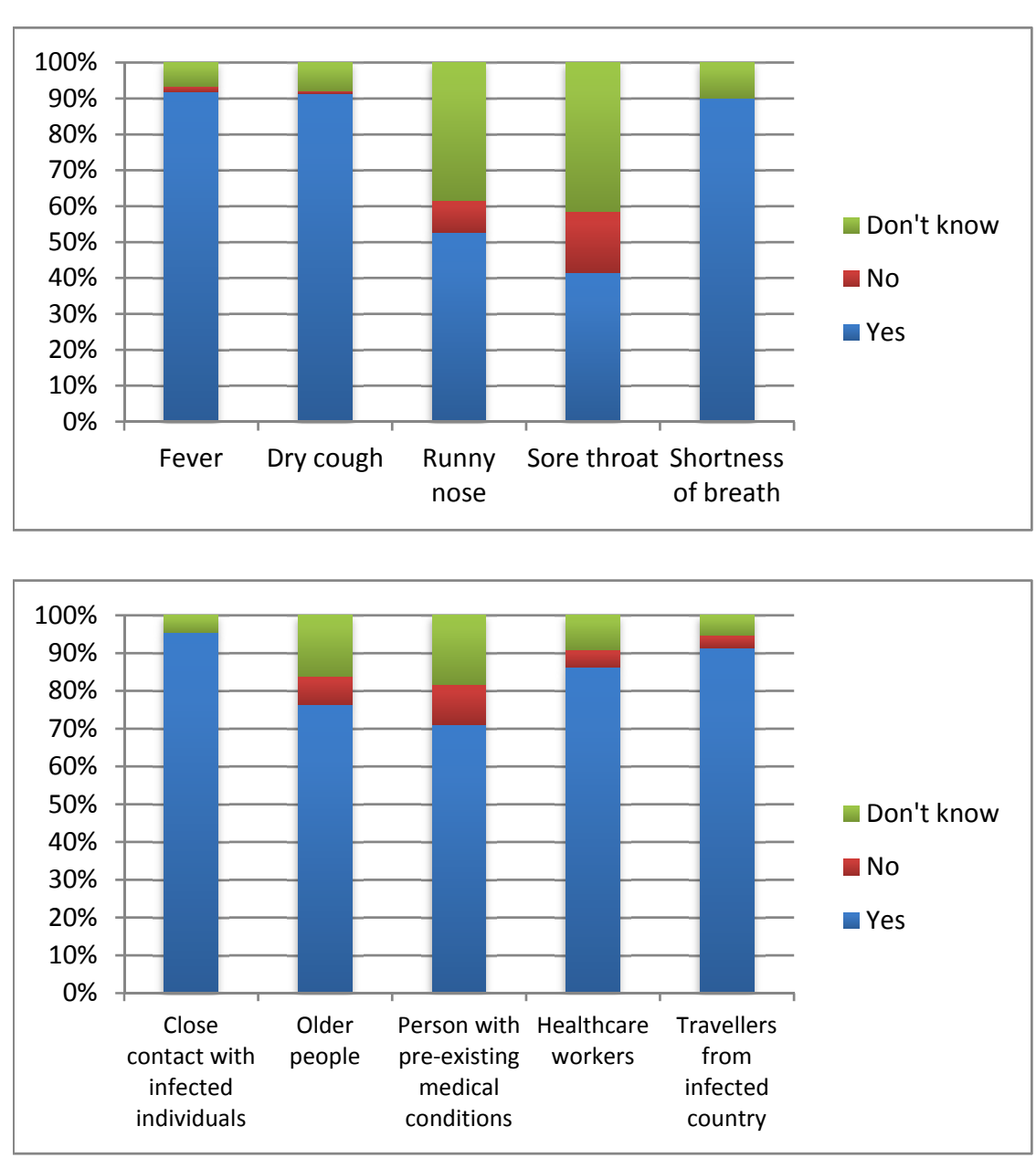

Fig. 1. Knowledge regarding symptoms of COVID-19 (top), knowledge regarding risk factors of COVID-19 (bottom)

their practices related to infection control measures as recommended by WHO. The best practice was observed in use of masks, as around $90 \%$ of health care workers responded that they wear either surgical or N-95 masks during patient contact, whereas the worst practice was found in use of gloves, where more than $40 \%$ of participants admitted that 


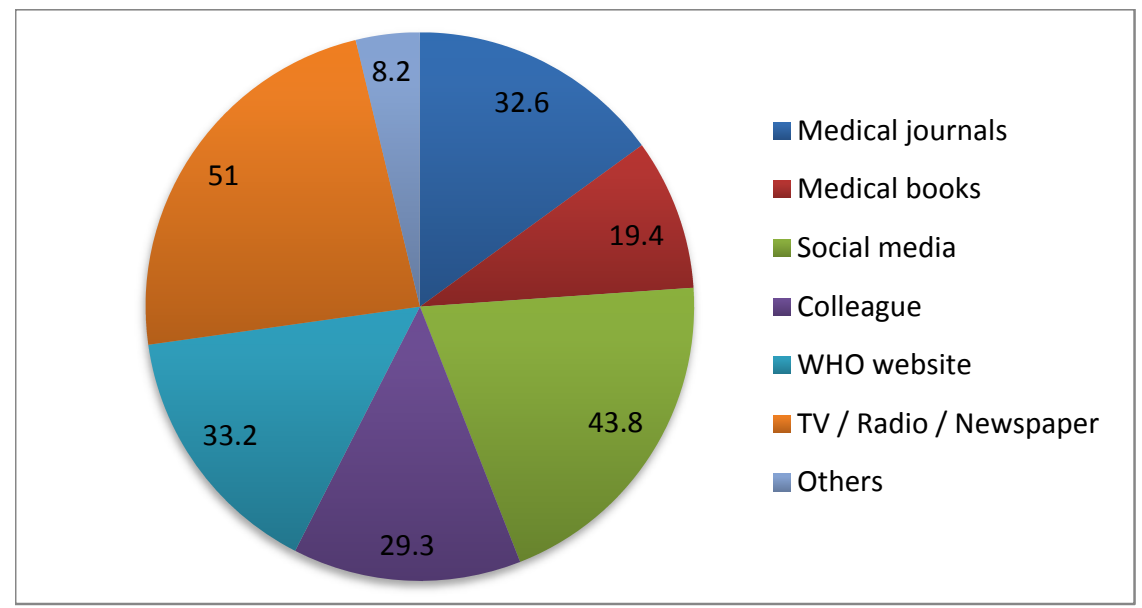

Fig. 2. Sources of information regarding COVID-19

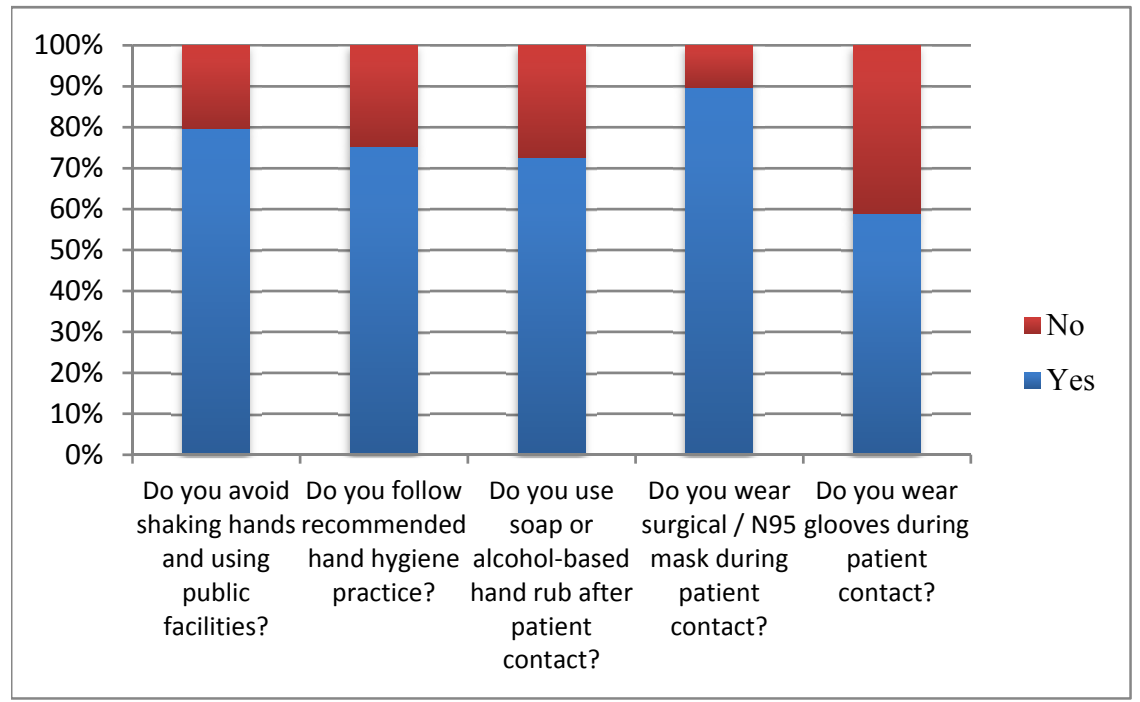

Fig. 3. Infection control practices of health care workers

they do not perform this practice routinely during patient contact (Fig. 3).

Table 3 shows the knowledge, attitude, practice, and perceived stress scores of the study population. More than half of all health care workers had "good knowledge", whereas around two-thirds of doctors and only one-third of allied health professionals scored "good knowledge". It was found that females and those living with family had better knowledge scores than males and those who were living without their families $(\mathrm{p}<0.05)$. Most of doctors, nurses,

Table 3. Knowledge, attitude, practice, and perceived stress scores of the study population

\begin{tabular}{|c|c|c|c|c|c|c|}
\hline & & \multicolumn{3}{|c|}{ Health care workers } & \multirow[b]{2}{*}{$\begin{array}{l}\text { Total } \\
\mathrm{N}(\%)\end{array}$} & \multirow[t]{2}{*}{ p-value } \\
\hline & & $\begin{array}{l}\text { Doctors } \\
\text { N }(\%)\end{array}$ & $\begin{array}{l}\text { Nurses } \\
\text { N (\%) }\end{array}$ & $\begin{array}{c}\text { Allied health professionals } \\
\mathrm{N}(\%)\end{array}$ & & \\
\hline Number of participants & & $180(59.2)$ & $76(25.0)$ & $48(15.8)$ & $304(100.0)$ & \\
\hline \multirow{3}{*}{ Knowledge score ${ }^{b}$} & Good knowledge & $116(64.4)$ & $33(43.4)$ & $16(33.3)$ & $165(54.3)$ & 0.00 \\
\hline & $\begin{array}{l}\text { Moderate } \\
\text { knowledge }\end{array}$ & $56(31.1)$ & $31(40.8)$ & $12(25.0)$ & $99(32.6)$ & \\
\hline & Poor knowledge & $8(4.4)$ & $12(15.8)$ & $20(41.7)$ & $40(13.2)$ & \\
\hline \multirow[t]{3}{*}{ Attitude score ${ }^{b}$} & Good attitude & $145(80.5)$ & $57(75.0)$ & $26(54.2)$ & $228(75.0)$ & 0.00 \\
\hline & Moderate attitude & $28(15.6)$ & $18(23.7)$ & $22(45.8)$ & $68(22.4)$ & \\
\hline & Poor attitude & $7(3.9)$ & $1(1.3)$ & $0(0.0)$ & $8(2.6)$ & \\
\hline \multirow[t]{3}{*}{ Practice score $^{\mathrm{b}}$} & Good practice & $119(66.1)$ & $38(50.0)$ & $22(45.8)$ & $179(58.9)$ & 0.00 \\
\hline & Moderate practice & $34(18.9)$ & $26(34.2)$ & $8(16.7)$ & $68(22.4)$ & \\
\hline & Poor practice & $27(15.0)$ & $12(15.8)$ & $18(37.5)$ & $57(18.8)$ & \\
\hline \multirow[t]{4}{*}{ Perceived stress score } & No stress & $2(1.1)$ & $1(1.3)$ & $10(20.8)$ & $13(4.3)$ & 0.00 \\
\hline & Mild stress & $22(12.2)$ & $12(15.8)$ & $14(29.2)$ & $48(15.8)$ & \\
\hline & Moderate stress & $87(48.3)$ & $41(53.9)$ & $8(16.7)$ & $136(44.7)$ & \\
\hline & Severe stress & $69(38.3)$ & $22(28.9)$ & $16(33.3)$ & $107(35.2)$ & \\
\hline
\end{tabular}

${ }^{a}$ Calculated using chi-square for categorical data; a $p$-value $<0.05$ was considered statistically significant.

${ }^{\text {bS }}$ cores were based on modified Bloom's cut off point. 


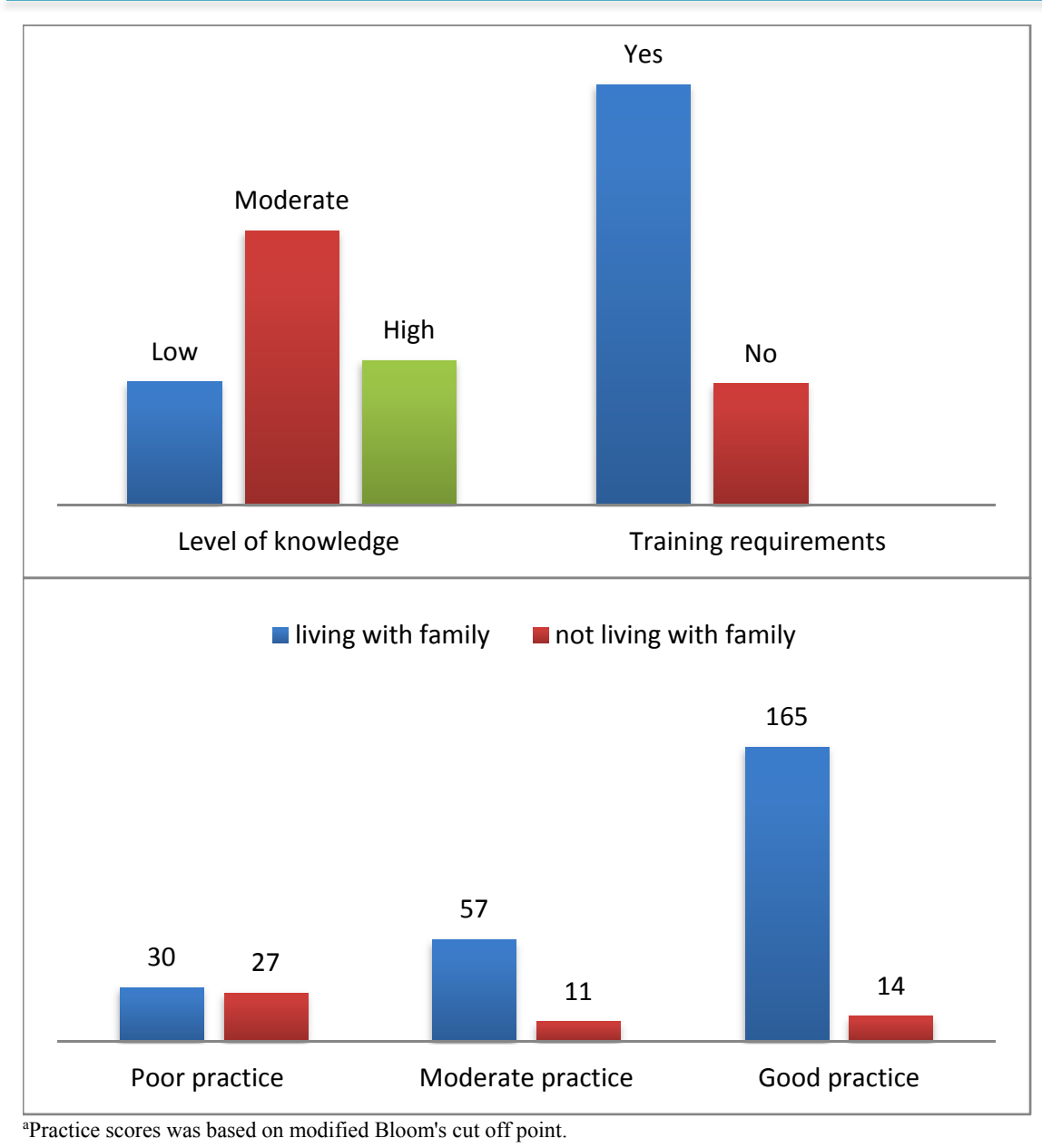

Fig. 4. Level of knowledge and requirement of training regarding COVID-19 and other emerging infectious diseases according to health care workers (top), practice scores ${ }^{\mathrm{a}}$ for health care workers who are living with or without family (bottom).

and allied health professionals $(80.5 \%, 75.0 \%, 54.2 \%$, respectively) had "good attitude". Similarly, more than half of health care workers practiced almost all infection control measures and had "good practice". Good practice was followed majorly by doctors $(66.1 \%)$, then nurses $(50 \%)$, and least by allied health professionals $(45.8 \%)$. Practice scores were statistically significant for marital status, living status, and gender $(\mathrm{p}<0.05)$, while attitude scores were statistically significant for marital status and years of experience $(\mathrm{p}<0.05)$. Stress levels were highest among doctors, with $38.3 \%$ having severe stress and $48.3 \%$ moderate stress. Around $80 \%$ of participants had perceived "moderate stress" or "severe stress" (Table 3).

The respondents were further questioned regarding their level of knowledge and training requirement concerning COVID-19 and other emerging infectious diseases. More than half of health care workers rated their level of knowledge as "moderate" and most of the population $(\mathrm{n}=236 ; 78 \%)$ was inclined towards need of training (Fig. 4). Figure 4 also shows that most of those health care workers who were living with family at the time of COVID-19 pandemic had a "good practice", while most who were living without families had a "poor practice". Practice score had a statistically significant association with living status of participants $(\mathrm{p}<0.05)$.

We observed a statistically significant association between the participants' age, gender, years of experience, having children, and living with or without family with perceived stress scores (Table 4). Almost half of our respondents $(42.8 \%)$ claimed that lack of personal protective equipment (PPE) would often lead to stress, and $42.1 \%$ of health care workers admitted that they often feel stressed because they could transmit COVID-19 to their family or friends. Around one-third of participants blamed the lack of vaccination and treatment to often cause them stress. Participants who were younger, were females, had fewer years of experience, had children, and were living with their families at the time of COVID-19 pandemic had more stress than their counterparts. No statistically significant relationship was found between marital status and perceived stress scores of participants (Table 4).

Figure 5 shows the association of perceived stress scores with attitude and practice $(\mathrm{p}<0.05)$ of health care workers. Participants with a higher level of stress mainly had better attitudes and practices; $93 \%$ and $85 \%$ of health care workers with "good attitude" and "good practice", respectively, had either perceived "moderate stress" or "severe stress". 
Table 4. Perceived stress scores of the study population

\begin{tabular}{|c|c|c|c|c|c|c|c|}
\hline & & \multicolumn{3}{|c|}{ Perceived stress score } & & \multirow[b]{2}{*}{$\begin{array}{l}\text { Total } \\
\text { N }(\%)\end{array}$} & \multirow[t]{2}{*}{ p-value } \\
\hline & & $\begin{array}{l}\text { No stress } \\
\text { N }(\%)\end{array}$ & $\begin{array}{l}\text { Mild stress } \\
\mathrm{N}(\%)\end{array}$ & $\begin{array}{c}\text { Moderate stress } \\
\text { N }(\%)\end{array}$ & $\begin{array}{c}\text { Severe stress } \\
\mathrm{N}(\%)\end{array}$ & & \\
\hline Age (mean) \pm SD & & $40.46 \pm 9.20$ & $32.17 \pm 8.86$ & $33.36 \pm 8.72$ & $35.77 \pm 7.47$ & $34.32 \pm 8.51$ & 0.00 \\
\hline Gender & $\begin{array}{l}\text { Female } \\
\text { Male }\end{array}$ & $\begin{array}{c}3(23.1) \\
10(76.9)\end{array}$ & $\begin{array}{l}34(70.8) \\
14(29.2)\end{array}$ & $\begin{array}{l}68(50.0) \\
68(50.0)\end{array}$ & $\begin{array}{l}61(57.0) \\
46(43.0)\end{array}$ & $\begin{array}{l}166(54.6) \\
138(45.4)\end{array}$ & 0.01 \\
\hline $\begin{array}{l}\text { Years of experience } \\
\text { (mean) } \pm \text { SD }\end{array}$ & & $12.15 \pm 7.58$ & $6.85 \pm 6.01$ & $6.72 \pm 6.35$ & $10.00 \pm 7.96$ & $8.13 \pm 7.15$ & 0.00 \\
\hline Marital status & Yes & $8(61.5)$ & $28(58.3)$ & $85(62.5)$ & $81(75.7)$ & $202(66.4)$ & 0.09 \\
\hline & No & $5(38.5)$ & $20(41.7)$ & $51(37.5)$ & $26(24.3)$ & $102(33.6)$ & \\
\hline Have children & Yes & $2(25.0)$ & $21(75.0)$ & $59(69.4)$ & $67(82.7)$ & $149(73.8)$ & 0.00 \\
\hline & No & $6(75.0)$ & $7(25.0)$ & $26(30.6)$ & $14(17.3)$ & $53(26.2)$ & \\
\hline $\begin{array}{l}\text { Living with family at } \\
\text { the time of COVID-19 }\end{array}$ & Yes & $7(53.8)$ & $40(83.3)$ & $111(81.6)$ & $94(87.9)$ & $252(82.9)$ & 0.02 \\
\hline outbreak & No & $6(46.2)$ & $8(16.7)$ & $25(18.4)$ & $13(12.1)$ & $52(17.1)$ & \\
\hline
\end{tabular}

SD: Standard deviation

${ }^{a}$ Calculated using chi-square for categorical data and one-way ANOVA test for continuous data; $p$-value of $<0.05$ was considered statistically significant.
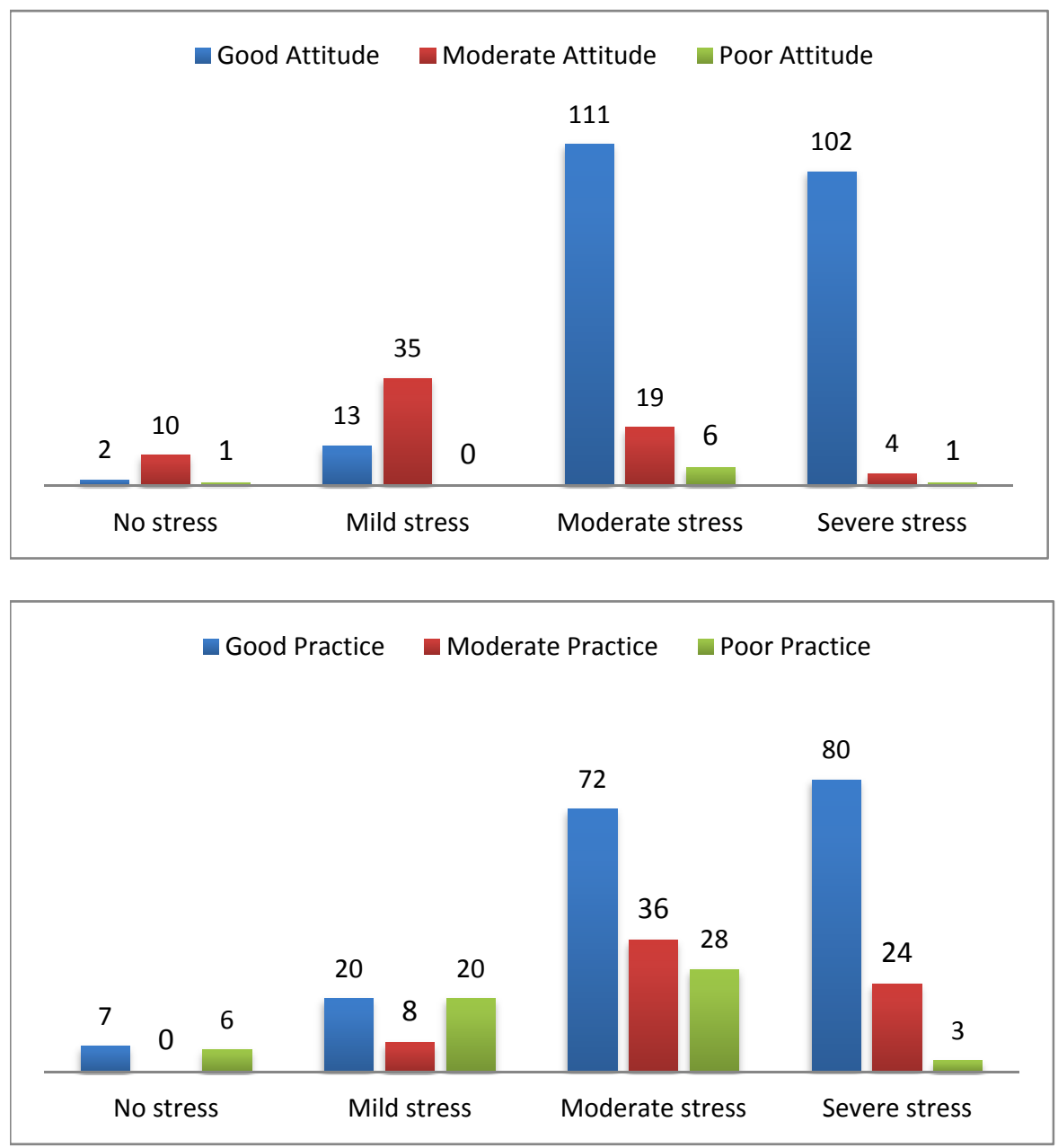

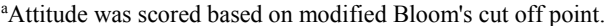

bractice was scored based on modified Bloom's cut off point.

Values on top of bar chart shows number of participants.

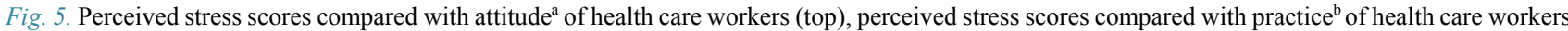
(bottom).

\section{Discussion}

In the outbreak of a pandemic like COVID-19, the HCWs who form the front line force are risking their own lives in the process, are at risk of infection and psychological distress $(9,11)$. Not only do they have to be present to cater to the infected patients, but they are also being approached to increase awareness about the disease in the population and

http://mjiri.iums.ac.ir

Med J Islam Repub Iran. 2020 (7 Oct); 34.132. 
describe various preventative measures. These HCWs having close contact with infected patients play a decisive role in infection control (18). As a higher level of knowledge and better practice of HCWs leads to increased awareness in general population, we, aimed to assess these parameters in people related to different fields of the health care system and also inquired about their stress levels to evaluate the effect this pandemic is having on them in Pakistan (5).

Our study found that more than half of HCWs have "good knowledge", "good attitude", and "good practices". These results support another study that found 93.2\% HCWs with good knowledge, the majority with a positive attitude, and $88.7 \%$ with good practice (19). This high level of knowledge, attitude, and practice is likely, because at the time of this study, the pandemic has already gained immense importance and various measures have been taken to increase awareness among people. When we compared different professions, more doctors were found to have good knowledge $(64.4 \%)$, followed by nurses (43.4\%). Likewise, $80.5 \%$ of doctors showed good attitude, while this number was lower in allied health professionals $(54.2 \%)$. Good practice was followed majorly by doctors $(66.1 \%)$, then nurses $(50 \%)$, and least by allied health professionals (45.8\%). Higher awareness among doctors has also been established in another research, where physicians seemed to be most aware of the signs and symptoms of COVID-19, indicating that awareness level is linked to the profession of an individual (20).

In accordance with a study conducted on nurses that found $56.5 \%$ of respondents have knowledge about the disease transmission and its symptoms, and another research conducted in Vietnam which yielded $72.8 \%$ of correspondents recognizing the symptoms correctly, the majority of HCWs in our study $(90.1 \%)$ also knew the transmission route of COVID-19 $(3,21)$. More than $90 \%$ recognized fever, cough, and shortness of breath as symptoms the disease presents with, which is in line with another research that yielded $85.4 \%$ of respondents being aware of the symptoms (22). This is understandable as the virus most commonly presents with these symptoms; however, other symptoms like nausea, vomiting, diarrhea, body aches, and muscle pain should also be kept in mind (1). Knowing the risk factors also helps scrutinize people and more than $70 \%$ of HCWs identified common risk factors, the most popular ones being "close contact with infected individuals" (95\%) and "travelers from infected countries" (92\%). Even though the majority answered the responses correctly regarding the incubation period $(77.3 \%)$, only half of the respondents $(52.3 \%)$ knew the fatality rate correctly, which can be a major barrier in explaining to the population the gravity of the prevailing condition.

Similar to a study that reported $98.2 \% \mathrm{HCWs}$ agreeing to the fact that COVID-19 patients should be kept in isolation, $82.3 \%$ of our respondents also agreed to this (3). The understanding of the need to isolate patients well reflects the knowledge of transmission that workers have and how in the absence of a vaccine, isolation may be the most effective method of prevention. Furthermore, $83.9 \%$ of participants agreed that overcrowded emergencies and poor hand hygiene increase the risk of infection, while $31.3 \%$ strongly agreed that it was lack of knowledge that led to increased risk of infection. The results are in line with a research that found a high proportion of respondents who agreed that emergency department overcrowding, poor hand hygiene, and lack of mask use contributed to the risk of HCW being infected with MERS-CoV (12). The same research also identified a large majority of participants who reported they were more eager to apply infection control measures since the onset of MERS-CoV in the Kingdom of Saudi Arabia (12). However, the fact that only $31.9 \%$ of HCWs in our study strongly agreed to continue to apply preventative measures after the outbreak means that there is still a dire need to inculcate good hygiene habits in HCWs to prevent future outbreaks.

The major sources of information regarding the disease were found to be TV/radio/newspaper, social media, and the WHO website in decreasing order of popularity, which is in contrast to another study that found social media to be the number 1 source for seeking information (3). The reason for this difference could be the increasing campaigns that are encouraging people to use more reliable sources of information and discouraging people from blindly believing unverified information on social media platforms. A number of researches have highlighted the negative impact of fake news surfacing over media on the population. An example is how media headlines like "China kids stay home" and "China is the real sick man of Asia" have misled members of the public and increased racial discrimination against individuals of Chinese descent outside China (23). Another example is the spread of fake news regarding the use of alcohol-based beverages being useful in the treatment of COVID-19 in Iran (24). Because the beverages have to be smuggled in Iran to be consumed, several patients ended up with methanol intoxication (24).

Among various preventive practices employed, wearing masks was found to be the most popular (about 90\%), followed by avoidance of public facilities and handshakes $(80 \%)$. Around $70 \%$ of respondents followed hand hygiene and washed their hands after patient contact. This is in contrast with another research conducted during the MERS outbreak that found handwashing to be the most popular practice and only half of the respondents stated that they wear masks (12). Unfortunately, more than $40 \%$ of our respondents stated that they do not use gloves during patient interaction, which is possible because of lack of habit among HCWs, as it is not a common practice in Pakistan to wear gloves during clinics. Furthermore, the lack of resources, especially in government/public sector hospitals, may also be a barrier towards following all preventative measures.

Even though the most $(78 \%)$ of participants assessed their knowledge to be 'moderate', it was reassuring to see that they were inclined towards the need for further training. This is consistent with another research in which the most of the HCWs $(\geq 72.3 \%)$ indicated they are in need of educational courses and training about the MERS-CoV, Ebola, and other emerging infectious diseases (12). When practices were compared, people living with families had better practices than those living without a family. This is 
understandable because of the greater sense of responsibility that comes with having a family and the fear that they may spread the infection to their loved ones, especially the more susceptible members of the family.

Our study also yielded high levels of stress among HCWs; $44.7 \%$ with moderate stress and $35.2 \%$ with severe stress. Compared to this, a study reported more than $70 \%$ of HCWs to have reported psychological distress (11). Distress may be due to feelings of vulnerability and concerns about health of self, spread of the virus, health of family and others, inadequate knowledge about the virus, increased workload, overwhelming media news, and stigmatization $(9,11,12)$. Almost half of our respondents $(42.8 \%)$ claimed that lack of PPE would often lead to stress, while around one- third of participants blamed the lack of vaccination and treatment to often cause stress. This is in line with a study on MERS where safety was found to be the main concern for health care workers (16).

Stress levels were highest among doctors (38.3\% with severe stress and $48.3 \%$ with moderate stress), while most nurses $(53.9 \%)$ had moderate stress. Among allied health professionals, $33.3 \%$ had severe stress. The study finds that the doctors among rest of the medical staff had greater level of responsibility and having better understanding of the disease and associated risks, which may have led to higher level of stress.

Furthermore, stress levels were found to be higher in participants who were younger, were females, had fewer years of experience, had children, and were living with their families. Being female as one of the risk factors for developing stress symptoms has already been established in previous research (9). People, particularly parents, had greater stress levels as they feared the spread of disease to their children who are more prone to contracting the disease and incurring death, which was asserted by countrywide awareness programs. To support this argument, about $42.1 \%$ of respondents of our survey feared transmitting the disease to their family members and friends. Few risk factors to increase the stress are lower levels of specialized training, preparedness, and job experience, which can be associated with the fact that such pandemic occurs once in a lifetime and managing such a situation becomes difficult considering its rarity (25). Finally, young individuals, who represent half of the population of the country, are also susceptible to this virus due to the exposure yielded while managing the daily outdoor activities like grocery shopping, etc. No association was, however, found between marital status and stress levels.

Importantly, our study yielded that higher stress levels lead to a better attitude and good practices as $93 \%$ and $85 \%$ of HCWs with "good attitude" and "good practice" had moderate to severe stress levels. This means that the more the respondents cared about the disease, the more they tried to prevent it from spreading.

Considering the findings of this research, we have proposed a few measures that may be taken to ease the battle against the coronavirus. Firstly, as a study suggested that infected HCWs form an important group in spreading the disease, the authorities should give immense importance to protecting HCWs from contracting the disease (26). This may be done by providing them with adequate personal protective equipment (such as masks, shields, proper attire, etc.). Following this will not only protect HCWs from the disease but as suggested by a study, assurance of personal safety is one of the major factors that will help alleviate stress levels among health care workers (16). Measures being taken to mitigate disease should also be made clear to decrease the stress.

The inclination of HCWs towards needing more training is good news in times of a pandemic for which no vaccine has yet been approved. HCWs should be promoted towards conducting research on various treatments and trying to devise vaccination for the virus; in the meanwhile, seminars should be conducted by professionals to provide them with authentic information regarding the virus. Gaining authentic information is also immensely important as during the ongoing pandemic, the spread of misinformation may lead to xenophobia (2). On an individual level, using stringent protective measures universally for all patients, using disposable scrubs at work, and minimizing outside exposure in the form of semi-quarantine are few of the measures that have shown to help staff cope with these tough times (16).

The study faced some limitations worth mentioning. First, the survey was conducted online via Google, which may have led to recall bias. Second, the questionnaires were in English, which may have been a barrier in understanding the interviewees. Third, the responses recorded were majorly from urban population, and responses from rural population would be different considering difference in working conditions. Fourth, the sample was not randomized and not matched based on age or gender, etc. Participants with preexisting psychiatric or stress-related disorders were not considered. Nonresponse bias may exist as the response rate in the survey was low. Finally, our study did not differentiate responses from front line workers and non-front line workers, which may be assessed by future, larger-scale studies.

\section{Conclusion}

Our study yielded relatively good knowledge, attitude, and practice among $\mathrm{HCWs}$; however, some areas were identified that need to be worked on. HCWs were acquiring knowledge from relatively less authentic sources, so they should be educated about more reliable sources that may be used and encouraged to be vigilant in verifying any information that they come across before conveying it to others. We also found high levels of stress among HCWs, and main stressors were found to be personal safety, family safety, and lack of information regarding upcoming advances in the treatment of COVID-19. Therefore, the government should take measures to mitigate these stress levels to produce a strong front line force to combat COVID-19. Our study suggests that better training programs and promotion of preventative measures, along with providing adequate PPE and ensuring life safety of HCWs, will most likely help in releasing this stress among them, leading to better attitude and practice. 
Conflict of Interests

The authors declare that they have no competing interests.

\section{References}

1. Kakodkar P, Kaka N, Baig MN. A comprehensive literature review on the clinical presentation, and management of the pandemic coronavirus disease 2019 (COVID-19). Cureus. 2020;12(4):e7560.

2. Lai CC, Shih TP, Ko WC, Tang HJ, Hsueh PR. Severe acute respiratory syndrome coronavirus 2 (SARS-CoV-2) and coronavirus disease-2019 (COVID- 19): the epidemic and the challenges. Int J Antimicrob Agents. 2020;55(3):105924

3. Huynh G, Nguyen TN, Tran VK, Vo KN, Vo VT, Pham LA. Knowledge and attitude toward COVID-19 among healthcare workers at district 2 hospital, Ho Chi Minh City. Asian Pac J Trop Med. 2020;13(6):260-5

4. Fan Y, Zhao K, Shi ZL, Zhou P. Bat coronaviruses in China. Viruses. 2019;11(3):210.

5. Zhong BL, Luo W, Li HM, Zhang QQ, Liu XG, Li WT, et al. Knowledge, attitudes, and practices towards COVID-19 among Chinese residents during the rapid rise period of the COVID-19 outbreak: a quick online cross-sectional survey. Int J Biol Sci. 2020;16(10):174552.

6. World Health Organization. Q\&A on coronaviruses (COVID-19) 2020. Accessed March 5, 2020. Available from: https://www.who.int/emergencies/diseases/novel-coronavirus-2019/question-and-answers-hub/qa-detail/q-a-coronaviruses.

7. Ozamiz-Etxebarria N, Dosil-Santamaria M, Picaza-Gorrochategui M, Idoiaga-Mondragon N. Stress, anxiety, and depression levels in the initial stage of the COVID-19 outbreak in a population sample in the northern Spain. Cad Saude Publica. 2020;36(4):e00054020.

8. World Health Organization. WHO coronavirus disease (COVID-19) dashboard 2020. Accessed June 1, 2020. Available from: https://covid19.who.int/.

9. Zhang WR, Wang K, Yin L, Zhao WF, Xue Q, Peng M, et al. Mental health and psychosocial problems of medical health workers during the COVID-19 epidemic in China. Psychother Psychosom. 2020;89(4):24250 .

10. Remuzzi A, Remuzzi G. COVID-19 and Italy: what next? Lancet 2020;395(10231):1225-28.

11. Lai J, Ma S, Wang Y, Cai Z, Hu J, Wei N, et al. Factors associated with mental health outcomes among health care workers exposed to coronavirus disease 2019. JAMA Netw Open. 2020;3(3):e203976.

12. Alsahafi AJ, Cheng AC. Knowledge, attitudes and behaviours of healthcare workers in the Kingdom of Saudi Arabia to MERS coronavirus and other emerging infectious diseases. Int J Environ Res Public Health. 2016;13(12):1214.

13. Joseph B, Joseph M. The health of the healthcare workers. Indian J Occup Environ Med. 2016;20(2): 71-2.

14. Gaur V. An overview of redefining paradigm: India's allied health professional. Int J Biochem Biomed Res. 2018; 1(1):20-34

15. World Health Organization. Protect yourself and others 2020. Accessed March 7, 2020. Available from: http://www.emro.who.int/ health-topics/corona-virus/protect-yourself-and-others.html\#accordion pane5

16. Khalid I, Khalid TJ, Qabajah MR, Barnard AG, Qushmaq IA. Healthcare workers emotions, perceived stressors and coping strategies during a MERS-CoV outbreak. Clin Med Res. 2016;14(1):7-14.

17. Mahadaviazad H, Keshtkar V, Emami MJ. Osteoporosis guideline awareness among Iranian family physicians: results of a knowledge, attitudes, and practices survey. Prim Health Care Res Dev. 2018;19(5):485-91.

18. Kharma MY, Alalwani MS, Amer MF, Tarakji B, Aws G. Assessment of the awareness level of dental students toward Middle East Respiratory Syndrome-coronavirus. J Int Soc Prev Commun Dent. 2015;5(3):163-9.

19. Saqlain M, Munir MM, Rehman SU, Gulzar A, Naz S, Ahmed Z, et al. Knowledge, attitude, practice and perceived barriers among healthcare professionals regarding COVID- 19: a cross-sectional survey from Pakistan. J Hosp Infect. 2020;105(3):419-23.

20. Khan S, Khan M, Maqsood K, Hussain T, Noor-Ul-Huda, Zeeshan M. Is Pakistan prepared for the COVID-19 epidemic?: A questionnairebased survey. J Med Virol. 2020;92(7):824-32.

21. Nemati M, Ebrahimi B, Nemati F. Assessment of Iranian nurses' knowledge and anxiety toward COVID-19 during the current outbreak in Iran. Arch Clin Infect Dis. Published online ahead of prin 2020;15(COVID-19):e102848.

22. Ranjan R, Ranjan GK. Knowledge regarding prevention of novel coronavirus (COVID- 19): an electronic cross-sectional survey among selected rural community. Int J Trend Sci Res Dev. 2020;4(3):422-6.

23. Wen J, Aston J, Liu X, Ying T. Effects of misleading media coverage on public health crisis: a case of the 2019 novel coronavirus outbreak in China. Anatolia. 2020;31(2):331-6.

24. Soltaninejad K. Methanol mass poisoning outbreak: a consequence of COVID-19 pandemic and misleading message on social media. Int J Occup Environ Med. 2020;11(3):148-150.

25. Ricci Cabello I, Meneses Echavez JF, Serrano-Ripoll MJ, Fraile-Navarro D, Fiol de Roque MA, Moreno GP, et al. Impact of viral epidemic outbreaks on mental health of healthcare workers: a rapid systematic review. medRxiv. 2020

26. Kim TH. Institutional preparedness for infectious diseases and improving care. J Korean Med Assoc. 2015;58(7):606-10. 